\title{
ALIGNING ORGANIZATIONAL STRUCTURE TO THE MARKET
}

This article emphasises the powerful role structure plays in creating a marketdriven organization. Then it analyses the trade-offs between different organizational structures and higlights the ways in which many firms are adopting hybrid structures based around horizontal business processes. The article also describes some of the ways in which information technology can enable firms to achieve greater market effectiveness without losing economic eficiency.

As part of the overall configuration of the firm, structure plays a powerful role in creating a market-driven organization. The wrong structure can doom all other market-driven initiatives in the organization to failure. This article analyses the trade-offs between different organizational structures and highlights the ways in which many firmas are adopting hybrid structures based around horizontal business processes backed up with deep functional strengths. In today's context, this hybrid form involves fast decentralized decision-making using widely dispersed and shared in formation. The article also describes some of the ways in which in formation technology can enable firms to achieve greater market effectiveness without losing economic efficiency The implications of the analysis for the role of the marketing function are considered in an Appendix.

The ideal of an organization that can continuously adapt to changing market opportunities, competitive challenges, and customer requirements is now closer to being realized. Information technology and new approaches to organization design, along with sharp challenges to the restrictions of the traditional functional design, have led to an unprecedented era of organizational innovation. Now, more than ever before, it is the customer that drives the organization - not the other way around.

Underlying this fundamental reorientation are four premises:

- Firms will increasingly evolve toward a hybrid or hypertext form of organization - combining the best features of horizontal process and vertical functional forms - in order to get closer to their customers.

- There will be a great deal of variety in the hybrid designs that are adopted, depending on the alignment of the value strat- egy and the core capabilities that are exercised in the processes. This will dictate the relative importance of staff groups, function specialists and process teams.

- Advances in data networks will permit firms to link internal teams for better, faster decision making, and to devise more interactive strategies that use information from the customer rather than about the customer.

- As strategies become more interactive, leading to increased dialogue and collaboration with customers and channels, there must be greater dispersion of information and decision making throughout the organization.

In preparing to align all aspects of the organization to the market, a useful first step is to assess the current organizational design. The assessment you reach will help to answer basic questions such as the following:

$\Rightarrow$ Is your current structure interfering with your ability to align the organization with the market?

$\Rightarrow$ How could it be changed to make the firm more marketdriven?

$\Rightarrow$ If a radical move would be attacked by the "white blood cells" of the organization as a foreign intruder, are there grafted components or augmented strategies that might be more palatable and lead toward more substantial changes in the future?

Answering these questions is more challenging than it might at first appear. In 1994, Digital Equipment Corporation (DEC) set out to radically restructure itself to become closer to its market. It redesigned the organization to create autonomous minicompanies organized by customer type: the better to anticipate and 
serve customer needs. The intention was to get closer to customers and convince them to buy complete systems.

But several problems derailed the plan. First, each of the new businesses combined low-margin products and high-margin services, undermining sales of each. Second, most of the executives came from DEC's engineering departments and knew little of the industries they were serving. Most seriously, there was a major shift in the computer industry, in which the rise of standard hardware and software let customers build their own systems from various vendors.

The moral is that even the best-intentioned moves to align the organizational structure to the market can misfire. In DEC's case, its restructuring eroded critical capabilities which were lodged in technology process and development capabilities. The company was eventually forced to organize itself around specific product lines, such as workstations, servers and software.

\section{Tradeoffs and the Search for Optimal Design}

Continuous organizational flux is the norm in most firms. If you are not currently in the middle of a redesign, you are brooding on the deficiencies of the most recent effort, and casting about for a better approach. Frustrating, time-consuming, and seemingly unproductive as the constant rearranging seems, it is inherent in the design problem. There is no perfect design for all seasons. First, any design is the unsatisfying result of many trade-offs and compromises, as demonstrated in the case of DEC's reorganization. Adding to one side of the balance can detract from the other. Second, markets are also in flux, so what worked tolerably well yesterday will not work so well tomorrow. Third, our concepts of effective and feasible designs are being challenged by the changing economics and availability of information, and the compelling track-record of teambased organizations.

The ideal of a market-driven organization is to have all functional activities integrated and aligned in the delivery of superior customer value. The difficulty is that functional differences are deeply rooted in incentives, backgrounds and interests, time scales and task priorities. Any effort to improve alignment requires numerous contending forces to be balanced. These involve dilemmas that require management to do several contradictory things at once. It's like driving a car: you want to get to your destination quickly and also safely; you must watch the road ahead and also look behind and around you.

Some of the classic dilemmas are:

\begin{tabular}{|c|c|c|}
\hline $\begin{array}{l}\text { Maintain flexibility } \\
\text { with small units }\end{array}$ & versus & $\begin{array}{l}\text { Achieve economies } \\
\text { of scale }\end{array}$ \\
\hline
\end{tabular}

$\begin{array}{lll}\begin{array}{l}\text { Align with market } \\ \text { and geographies }\end{array} & \text { versus } & \begin{array}{l}\text { Develop and leverage } \\ \text { distinctive capabilities }\end{array}\end{array}$

Make it new and versus Be predictable and innovative

\section{Develop deep versus Subordinate functions to functional expertise process team Facilitate versus co-ordination and Eliminate overhead and unproductive activities} information sharing

These tradeoffs are inherent in the choice which has to be made between the four possible templates for designing the backbone of an organization:
$\rightleftharpoons$ product;
2 geography;
- market segmentation;
- market channels.

The first, and most prevalent is the product theme, which often dictates how divisions are created. Here commonality of product features or production process takes precedence. Within consumer packaged goods firms, the divisions are product-based and individual product or brand managers are responsible for charting the course of their products. They produce a co-ordinating logic for the functional activities of logistics, manufacturing, sales and so on. The second is the geographic template, which is used by some large money-center banks. The third option is to have the organization mirror the segmentation of the market. This is conceptually appealing but seldom found in a pure form. Instead, market managers may coexist with functional managers in a matrix structure, or parts of the organization may be focused on segments such as the high net worth segment in retail banking. The fourth option is to design around channels, such as a retailer with separate store and catalog groups.

Each organizational template imposes painful tradeoffs. In a product-based structure, it is difficult to tailor the offering to the needs of specific geographies or end-consumer segments. A geographic approach makes it difficult to share knowledge across regions and may increase costs through the duplication of activities. An end-user-segment approach, such as DEC tried to adopt, raises the risk of fragmentation and erodes deep product knowledge.

Organizational dilemmas and trade-offs have always been with us, but they have become sharper and less avoidable with the recognition that core competencies or capabilities are at the source of the most durable and valuable competitive advantages. These capabilities transcend the traditional boundaries and functions of an organization, and are enhanced by learning processes that span the entire organization (Hamel and Prahalad 1994). Sony's miniaturization capability or WalMart's mastery of supply-chain replenishment span the organization and its markets. Meanwhile, to achieve focus and gain intimate understanding of disparate markets, it is desirable to have businesses organized to target distinct markets.

There is no absolute or permanent solution to these challenges. Creating and recreating the organization is an on-going process, as described in the case of GE Plastics (see overleaf, which is an adagtation of Pangan 1994). Each shift to a new organizational form brings some unwanted side effects and 
each shift in the market creates new challenges to be addressed by the next organizational form.

\section{Layers of Complexity}

As markets become more complex, the trade-offs built into the design challenge become more constraining, and the organization finds it harder to respond to all the demands placed on it. New structures, functions, and activities have to be grafted on to meet these new demands. Each add-on serves a purpose but the cumulative effect is an increasingly unwieldy and complicated structure, which places intolerable demands on the ability of management to co-ordinate and integrate activities.

The experience of Procter \& Gamble (P\&G) with the organization of its marketing demonstrates how organizations accumulate complexity. $P \& G$ has traditionally been organized around product categories, often with complete functional organizations. As the product range expanded, the company began to add other brands, each needing a brand manager. Within detergents alone, there are nine brands, each with a fulltime associate and assistant brand manager working for the brand manager. Because each of these brands is competing within the same category, their work needs to be co-ordinated by a category manager: Otherwise, brand managers would spend their time unprofitably trying to steal sales from other P\&G brands.

The sales function also became more complex as the channels evolved. The most important to $P \& G$ are the large supermarkets, and warehouse clubs and mass merchandise chains.
Relations with each of these retail chains is managed by a national account manager who is supported by a customer service team of specialists in logistics, finance, and so forth.

These channels help P\&G reach the home. But there are other big markets such as laundries and hospitals with market segment managers that develop special programs. These sales roles are evolving under pressure from the largest accounts like Wal-Mart which does not want to have to deal with a different team for each $P \& G$ product: it wants a single point of contact to co-ordinate sales activities across the entire firm.

A similar structure is generally used within each of the major country markets, with local variations as needed. In a large country such as the US, there are many regfonal differences in tastes, requirements, and competitive realities. Consumer goods companies are increasngly adding market area managers to create programs that recognize these differences: what works in the Southwest won't work as well in the Northeast and vice versa.

The $P \& G$ marketing organization is a metaphor for any organization that breeds complexity in response to new demands. Each additional job function adds a bit more bureaucracy, slows down decisions because more people have to be consulted, and causes critical market knowledge to be dispersed to more points. Certainly, each of these jobs adds value or it would not have been justified in the first place; but the cumulative effect is to increase costs and reduce responsiveness. Sooner or later, the situation becomes intolerable and a search for a new organizational template begins.

\section{The Continuous Challenge of Complexity: General Electric Engineering Plastics Division}

When GE Plastics successfully launched its Lexan polycarbonate as a replacement for glass, a simple product-based organization structure was appropriate. During the sixties the emphasis was on converting customers from other materials, and this structure provided a sense of ownership, team responsibility, and accountability.

The structure continued to work into the seventies, even as GE Plastics introduced Noryl. This was another engineering plastic that suited applications such as auto dashboards, and personal computers. As the product line expanded, so did the number of competitors. During the eighties, growth slowed to single digits. Customers were more experienced with engineered plastics and more open to switching to lower-priced alternatives. The buying decision put increasing emphasis on price, manufacturability, and service. In the meantime, Noryl and Lexan were aiming at the same applications and competing more directly. By 1985, the autonomous product divisions were more a hindrance than a help. Customers were confused as Noryl and Lexan attacked each other - each claiming they were best for the other's applications. The costs of duplicate services - purchasing, service, finance, MIS - were mounting. Vested interests were solidly entrenched and resistant to change.

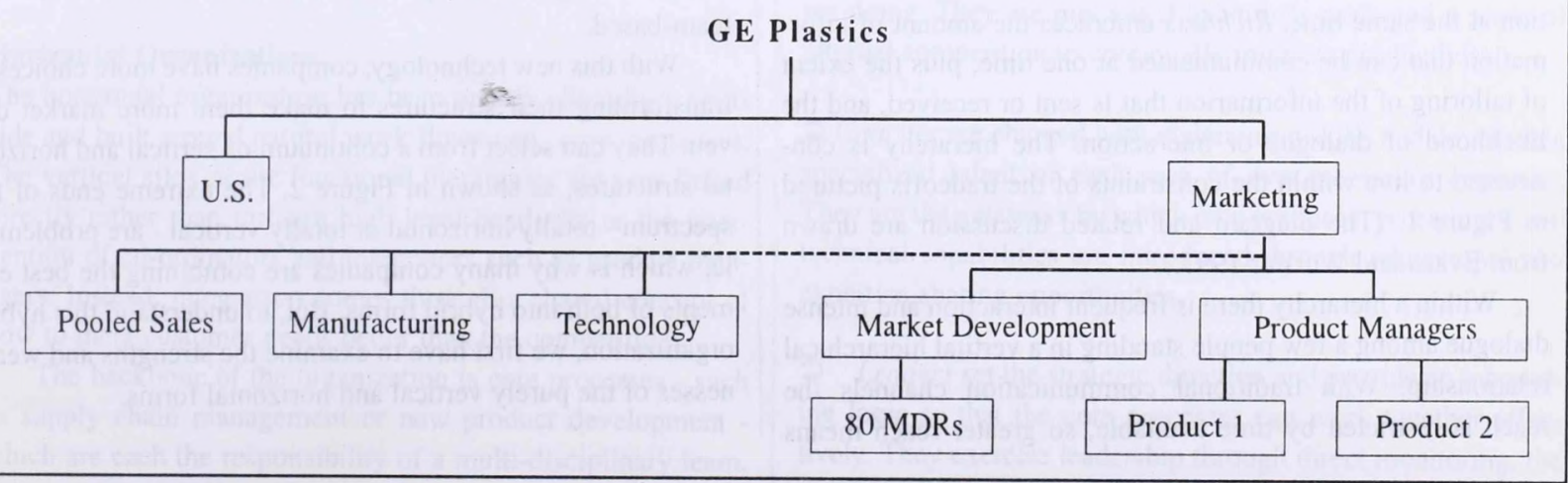


The solution was to divide GE Plastics into three geographic regions (America, Europe, and Pacific). Within each geography, marketing, sales, manufacturing, and technology were common functions for all products. Profit-and-loss responsibility resided with the geography bead. Marketing and product management became worldwide functions, with product managers the critical link for co-ordination within GE Plastics.

This solution resolved the problem of customer confusion, and enabled the business to get closer to customers. The new function of Market Development Rep (MDR) provided integrated solutions to final customers such as Ford. Many of the responsibilities of the Product Division general managers were assigned to product managers, including strategy, resource allocation, and pricing.

Although the new structure was clearly more market-driven, and moved the organization away from an intense focus on products, other problems emerged. The structure was more complex, with many more "indirect" reporting relationships, and the role of the global marketing management function was murky. Meanwhile more accounts wanted global solutions, leading to a need for global account managers who could maintain consistency. All these pressures for change lead to further adjustments to the structure - and the job will never end.

\section{Cutting the Gordian Knot: the Promise of Information Technology}

Will increasing market complexity continue to outrun the capacity of multi-product, multi-market organizations to cope? Is the answer to simply keep grafting more components, activities, co-ordinators and integrating functions onto an increasingly cumbersome structure? Cautiously, the answer is "no" because information technology is releasing us from the stifling premises of hierarchies. It can help cut through the raveled Gordian knot of these layered organizational structures.

Information technology allows us to challenge fundamental assumptions underlying traditional hierarchies (Webster 1997). These are based on a belief in unity of command, where there is only one reporting relationship. The span of control for any manager should then be no more than five-to-seven reporting relationships, to avoid going beyond the limit of direct communications. Another deep-seated belief about hierarchies is that authority should be commensurate with responsibility. Ambiguity about roles and responsibilities should be minimized with clear job descriptions. People who have lived within hierarchies for years are so comfortable with these principles they seldom rouse themselves to challenge them, despite all the frustrations of living with the consequences.

On closer scrutiny, these beliefs are predicated on the assumption that information flows cannot be rich und broad simultaneously. In fact, these are tradeoffs. Reach is determined by the number of people who share the same information at the same time. Richness embraces the amount of information that can be communicated at one time, plus the extent of tailoring of the informarion that is sent or received, and the likelihood of dialogue or interaction. The hierarchy is constructed to live within the constraints of the tradeoffs pictured in Figure 1. (The diagram and related discussion are drawn from Evans and Wurster 1997.)

Within a hierarchy there is frequent interaction and intense dialogue among a few people standing in a vertital hierarchical relationship. With traditional communication channels the reach is restricted by time available, so greater reach means adding more layers to the hierarchy. This inevitably leads to information being divided up more finely as it proceeds down the hierarchy, and introduces serious asymmetries or imbalances in the amount of information at various levels. Senior managers have greater power because information is valuable and they have a wider span for their knowledge base than their subordinates.

However, this structure interferes with the flow of information from the market. Information moves sluggishly up the hierarchy from the sensors that are in direct contact with the market. Top management will not be well-informed just betterinformed than anyone else.

Information technology changes the tradeoff between reach und richness. What would it be like if everyone could access the same data sources and communicate with everybody else with essentially zero cost und negligible friction und impediments? The emergence of the Internet, extranets, and intranets provide opportunities for broad und deep information flows throughout the organization und with external stakeholders. This creates the opportunity to move away from rigid hierarchies to create new organizational forms.

However, it does not mean that organizations are moving completely away from vertical structures. They are creating organizational hybrids, combining horizontal business processes and vertical specialist functions. Among the most important organizational innovations to enable closer market alignment are the emergence of hybrid structures that are flexible and team-based.

With this new technology, companies have more choices in transforming their structures to make them more market driven. They can select from a continuum of vertical and horizontal structures, as shown in Figure 2. The extreme ends of the spectrum - totally horizontal or totally vertical - are problematic, which is why many companies are combining the best elements of both into hybrid forms. But, to understand this hybrid organization, we first have to examine the strengths and weaknesses of the purely vertical and horizontal forms. 
Figure 1

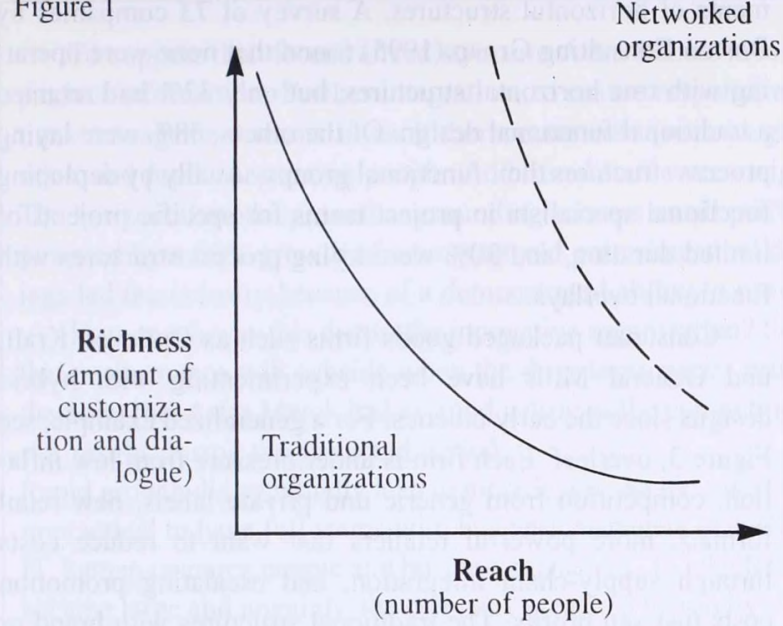

\section{Vertical Organizations}

The traditional vertital hierarchy is not quite a dinosaur. It can be a good approach for small firms with focused strategies und straightforward value propositions where the customers' needs are well known to all functions. "Line of sight" information sharing and strong leadership are sufficient to ensure alignment of functions with the market. Hierarchies also suffice when it is necessary to optimize costly, capital-intensive, and inflexible factories or systems. Because jobs are carefully divided into well-defined specialty activities, there is deep functional expertise.

The Achilles Heel of vertital hierarchies is co-ordination. It takes a lot of middle managers to collect front-line information and feedback, and broadcast and clarify top management intentions und priorities. These managers accrue power because they control information flow und allocate resources. Because these managers occupy und identify with a functional home, they are prone to optimize their own parochial activities but not talk to each other in a systematic way. The result is a lack of product integrity, slow response times and high costs. These problems are accentuated by mounting market complexity and the threat of competitors who adopt sense-und-respond strategies. Sooner or later the tension between the forces of inertia that lock firms into their comfortable but ineffective structure and the mounting forces of change forces consideration of other structures.

\section{Horizontal Organizations}

The horizontal organization has been turned - literally - on its side and built around natural work flows und core processes. The vertical silos of the functional hierarchies are now linked directly rather than through high-level hand-offs or the intervention of co-ordinators and integrators such as product managers. Instead, integration comes through a shared concept of how to meet customer needs better than the competition.

The backbone of the organization is core processes - such as supply chain management or new product development which are each the responsibility of a multi-disciplinary team.
Teams are accountable for external objectives such as customers' satisfaction with the outcome of the process, or performance-related to competitive benchmarks such as order-processing time. Information is readily shared with all team members through internal networks (usually Intranets) that eliminate the filtering und interpretation once done by intermediaries.

\section{Figure 2}

\section{Organization Design Continuum}

\section{Extensive}

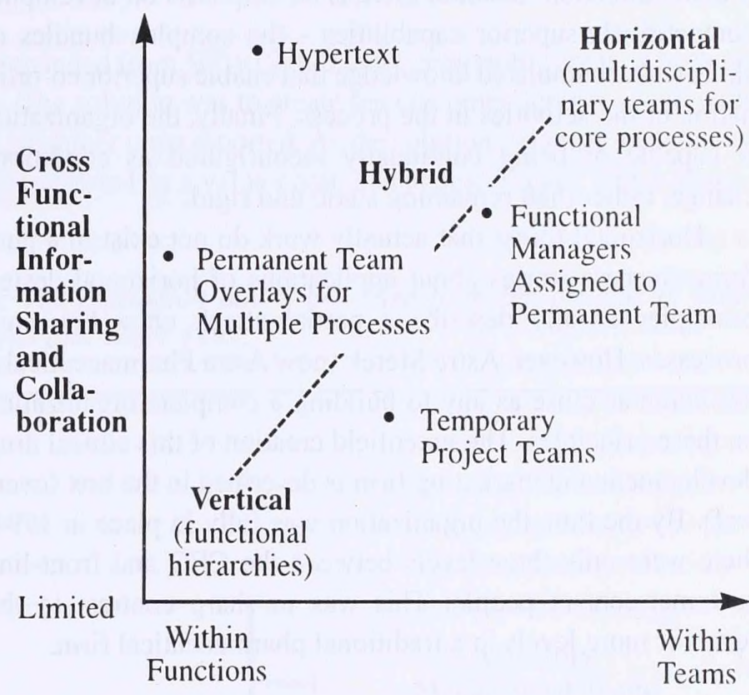

\section{Economies of Scale and Skill}

A distinguishing feature of the horizontal or process-oriented organization is the creation of new managerial roles (Hammer 1996). Gone are the familiar titles of "department manager", "section leader", "director" or "supervisor". In their places we find three different roles within a business unit:

Process owners who ensure that the processes they are responsible for are well-designed, oversee the day-to-day activities of the teams, and have ultimate responsibility for the team assigned to the processes. These people work hard to get the highest yield from their assets und resources, and are given abundant und immediate feedback on combine how well they are doing. They are motivated by stretch goals and a sense of internal competition to continually improve productivity.

O Coaches are charged with maintaining skills and developing specialized talent in each area of over necessary expertise. They are the gateways by which new practices, procedures, and technical capabilities are introduced through educational and expertise-sharing opportunities.

- Leaders set the strategic direction and provide an integrating logic so that the core processes can work together effectively. They exercise leadership through direct monitoring, the 
creation of operating principles that shape the assumptions of the rest of the organization and the allocation of resources. However their choices und decisions are not unilateral and topdown; instead, all of main players have an active role in the ongoing strategy dialogue.

Horizontal structures have several other distinguishing features, according to proponents. First, there are fewer layers, because there are fewer supervisory responsibilities in selfmanaged teams, and only a lean top management is needed to provide direction. Second, there is an emphasis on developing competitively-superior capabilities - the complex bundles of skills und accumulated knowledge that enable superior co-ordination of the activities in the process. Finally, the organization is capable of being continually reconfigured as conditions change, rather than remaining static und rigid.

Horizontal forms that actually work do not exist in a pure form. Success stories about applications of horizontal design principles usually describe a partial attack on a few core processes. However, Astra Merck (now Astra Pharmaceuticals) has come as close as any to building a complete organization on these principles. The greenfield creation of this ethical drug development and marketing firm is described in the box (overleaf). By the time the organization was fully in place in 1994 , there were only three levels between the CEO and front-line customer-contact people. This was in sharp contrast to the seven or more levels in a traditional pharmaceutical firm.

\section{Hybrid Organizations}

Most firms are not willing or able to shift to a purely horizontal form as Astra Merck did, und few are given a blank slate for designing a new organization. Instead, they are creating hybrid organizations that elements of vertical organizations with ele- ments of horizontul structures. A survey of 73 companies by Boston Consulting Group (1995) found that none were operating with true horizontal structures, but only $32 \%$ had retained a traditional functional design. Of the others, $38 \%$ were laying process structures their functional groups, usually by deploping functional specialista in project teams for specific projects of limited duration, and $30 \%$ were trying process structures with functional overlays.

Consumer packaged goods firms such as Unilever, Kraft, und General Mills have been experimenting with hybrid designs since the early nineties. For a generalized example, see Figure 3, overleaf. Each firm is under pressure from low inflation, competition from generic und private labels, new retail formats, more powerful retailers that want to reduce costs through supply-chain integration, and escalating promotion costs that sap profits. The traditional structures with brand or product managers responsible for co-ordination could not handle the increased stress.

Firms that create hybrid structures recognize that they need to foster vertical skills and disciplines such as the engineering skill to design ergonomically-sound products, the financial skills und experience to create the financial services that differentiate GE Lapital from its competitors, or the mastery of information technology that enables the seamless integration of a business und its customers. And despite the ambitious claims of the process engineers, there will always be internal handoffs, whether from research to product development or from the center to the field organization.

Hybrid structures combine horizontal business processes with integrating and specialist functions. Integrating functions such as marketing, strategy development, and human resource management provide the mechanisms for co-ordinating and allocating resources to the core processes. Specialist functions

\section{Astra Merck: an Antidote to Hierarchy}

Astra Merck has enthusiastically adopted a horizontal organization to build a billion-dollar ethical drug development and distribution firm with a solution-selling capability. The company was conceived out of an unusual set of circumstances. It was created as a stand-alone joint venture in 1992 to combine the heart and gastrointestinal drugs developed by AB Astra, a Swedish firm, with the US sales capabilities of Merck and Co. It also was seen as an opportunity to create a new and different model of a pharmaceutical company.

This greenfield approach was seen as the best way to deal with a major disruption in the market. Traditionally, drugs were sold to individual doctors through the detailing and sampling activities of large field sales forces. By 1993, the trend to managed care with centralized buying was well under way, seriously threatening these traditional relationships. Managed care buyers were more price sensitive and interested in a drug's cost-effectiveness, and restricted the access of the doctors in their network to only the drugs that satisfied these criteria. Meanwhile pharmaceutical firms were trying to rein in the very high costs of their traditional salesforces - which might exceed $2 \mathrm{~S}$ to $30 \%$ of sales.

When the new management team was given a clean sheet of paper, it dismissed most of the conventional hierarchical wisdom about how to organize. Instead it started from the outside in with multi-disciplinary teams as the basic building blocks. The structure of these teams was guided by a business architecture that linked $1 \mathrm{~S}$ business processes. A key element is the business unit team, which is responsible for one of 31 regions of the US, and carries a wide array of functions in addition to sales. Each unit has medical information scientists (who have the depth of knowledge to build peer relationships with the medical profession) plus customer support people (who provide information) and business managers (who concentrate on large accounts). These business units are designed to be highly autonomous and expert in their markets with the capability of rapidly pulling together creative solutions for individual customers. 
To support this decentralized structure Astra Merck invested heavily in company-wide systems such as those that access product information. Further integration, to ensure responsiveness to customer needs, was achieved with pharmaceutical solutions management teams in each therapeutic area (such as gastrointestinal) that included development, licencing, marketing, sales, and product-sourcing people. Additional staff were assigned to licencing, business development, and sourcing processes. The horizontal model proved a resounding success on all performance measures. By late 1998, sales had reached $\$ 4$ bn per year powered by a $60 \%$ growth of a ten-year-old gastrointestinal drug, Prilosec. Between 1997 and 1998, customer satisfaction ratings led the industry because of a demonstrated ability to provide solutions.

How much was this due to the innovative organization? Skeptics attribute success to the acceptance of Prilosec, and predict that performance will subside when the drug loses patent protection and becomes a generic. This is fair comment, but misses the point that Astra Merck had as good a drug as the competition, but was better equipped to exploit it rapidly and achieve superior results durrog the protected period.

Rapid growth did eventually lead to more layers. As the salesforce expanded from 500 to 2,400 in 67 geographic areas, it became impractical to have full teams with business managers in each area. The solution was to create ten customer centers - each with IT, human resource people and business managers - to which the 67 customer units reported. As the solutions-management teams became large and ungainly, the company created a hierarchy of teams directed by a value-chain management team, which sharpened accountability for decisions.

Note: In July 1998, Astra Merck was combined with Astra USA. The discussion above benefited fiom the insights of Matt Emmens, CEO of Astra Merck. Other sources include Cespedes 1995 and Yetter 1995.

Figure 3

Hybrid Organizations for Consumer Packaged Goods

\begin{tabular}{|l|l|}
\multicolumn{2}{|c|}{ CEO } \\
\hline Marketing \\
\hline Development (R\&D) \\
Purchasing \\
\hline Distribution \\
Manufacturing \\
Technology \\
Finance \\
Information \\
Systems
\end{tabular}$\quad \begin{aligned} & \text { Advertising } \\
& \text { Specialists } \\
& \text { Promotion } \\
& \text { Specialists } \\
& \text { Quality }\end{aligned} \quad \begin{aligned} & \text { Pricing } \\
& \text { Analysis } \\
& \text { Marketing } \\
& \text { Intelligence } \\
& \text { Specialists } \\
& \text { Competitive } \\
& \text { Analysis }\end{aligned}$

Administration

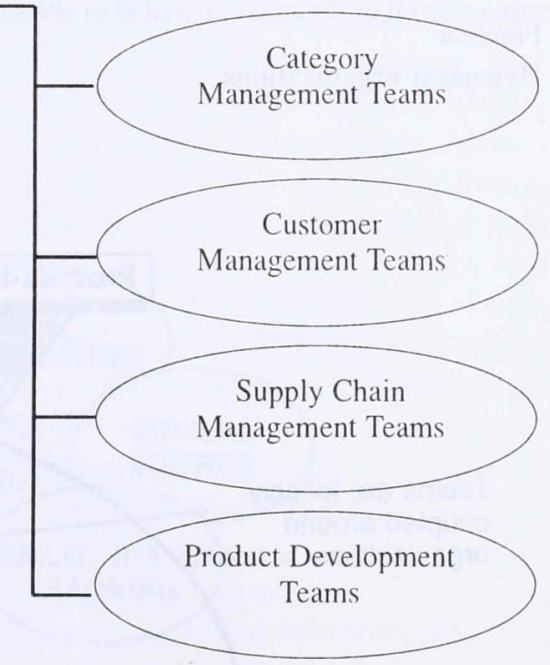

Category Management Teams: Responsible for leveraging deep understanding of the market and the equity of the brand name to formulate und communicate the value proposition to the consumer; composed of representatives from marketing, finance, sales, operations, and R\&D. is.

Customer Management Teams: Responsible for maximizing total performance with the major retail and trade customers, by building solid relationships and integrating operations for mutual cost savings; includes field sales, marketing, promotions, logistics, and sales.

Supply Chain Management Teams: Charged with the sourcing, production, and delivery for major product categories; representatives come from manufacturing, purchasing, distribution, und quality.

Product Development Teams: Find und develop product concepts that deliver compelling value propositions to target customers; includes R\&D, marketing, and manufacturing. 
such as $R \& D$ and marketing research are needed to provide technical expertise and replenish the horizontul processes with new ideas - either through new insights from outside the firm or the transfer of learning across teams. As a result, most firms start with "centers of excellence" based on traditional departments and disciplines, then modify the vertical function so it is more meaningful. Thus, sales might become customer interaction and engineering could be technical design. The coach who was once a functional manager - continues to play a central role.

Although there are many variants of the hybrid solutions to these problems, the main features of successful applications are the following:

2 Permanent teams overlaid on the existing functional structure. Three or four primary types of teams can be found - corresponding to the core processes of managing categories, customers, supply chains, and (sometimes) product development. Category management teams may look after line extensions and packaging innovations while new platforms or even breakthrough products will be assigned to a full-time new product development team. More details about these teams can be seen in Figure 3. The more complex the organization, the more teams are spawned. In 1996, Kraft had 35 category teams, 30 supply chain teams, and 175 customer teams. The popularity of category teams is a recognition that firms can no longer afford competition between their brands, and that for the other processes to work (and leverage common resources) there has to be co-ordination across brands.

O These teams are real - not temporary task forces. They actually run the day-to-day operations. Members spend all their time on team activities, although they have a reporting connection to a functional group. They are integrated into the team via meetings, e-mail, and access to shared databases. To keep them focused, they are evaluated on how well the category or retail account is performing agarost team objectives. All teams have access to specialized resources that are housed in the functions. This helps spread learning across teams. Thus, an interactive promotion specialist can serve a number of different category teams with expertise no single team could afford in on its own.

- Integration across processes. One of the painful lessons of re-engineering is that optimizing one or two carefully-chosen processes is unlikely to optimize the whole. Without mechanisms for integration, there will be new walls created, but these will be between processes rather than the usual silos between brands and functions. To overcome this tendency to fragmentation, there must be a common strategic logic. Some firms have strategic integration teams for the purpose of charting the over-

Figure 4

Hypertext organizations

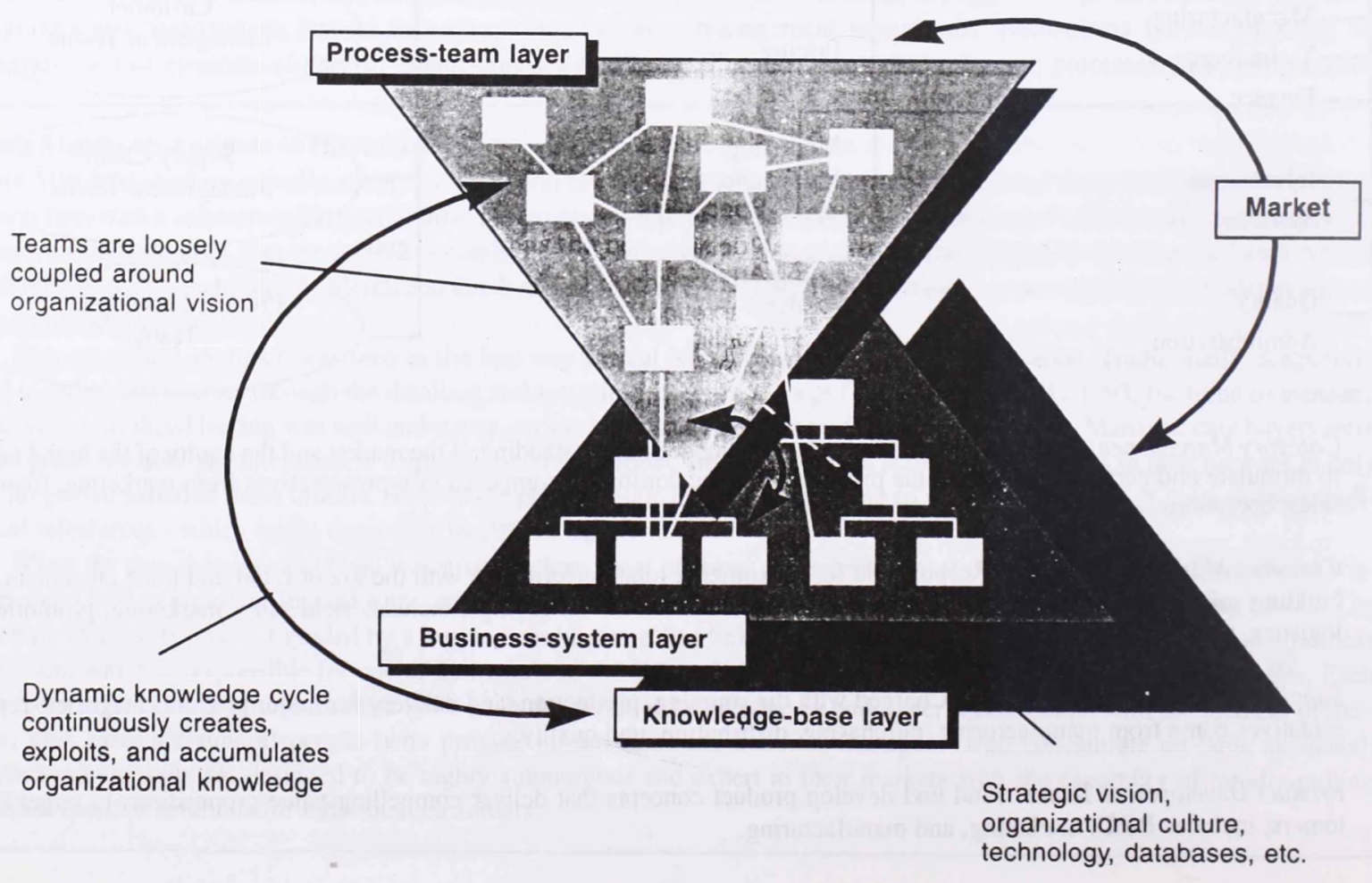


all direction. Who are the target consumers? What values are they seeking? What capabilities will we nurture and how will they be structured to gain advantage? How will demands for private labeling be met? How much investment in new products? and so on.

Other integrating devices include interlocked teams that share objectives and have joint members who serve on several teams. They can communicate the thinking of a category team devising a new package to the supply management team so no time is lost in putting it into production. (For further analysis of these issues see Boehm and Phipps 1996, Armstrong et al 1996 and Aufreiter et al 1996.)

\section{Hypertext Organizations}

With the continued development of information technology that facilitates information sharing, companies are creating new organizational forms to increase their connection to the market. The hybrid design is moving toward a hypertext form (Nonaka and Takeuchi 1995), shown in Figure 4. This organization is analogous to the interconnected layers of a computer hypertext program that enables one to drill below a text for greater detail and amplification.

On top is a process or project team layer where multiple teams manage horizontal processes or engage in knowledgecreating activities such as new product development or chart- ing a new interactive strategy. The team members are assigned from diverse functions or practice areas for the duration of the project. In the case of core processes, they would have a continuing commitment with the option of returning to a functional home.

In the middle is the functionally-structured business system layer that develops the expertise necessary to support the business strategy and provides a talent pool for the functional teams. This layer also creates opportunities for networking and sharing functional expertise - so learning is readily available to all teams. Where particular skills are needed by many teams, such as the design and sourcing of marketing research studies, the specialist with this knowledge may be permanently housed on this layer. These business systems are linked to each other and to the business processes by information technology rather than by a tradition.

The foundation is the "knowledge base" layer where cumulative organizational knowledge resides. This layer does not exist as a distinct organizational form, for it is composed of both the tacit knowledge contained in the corporate vision and culture and the explicit knowledge contained within the information systems. Members of the hypertext organization can readily shift from the context of one layer to another layer as circumstances change. However, someone belongs or reports to only one structure at a time - in contrast to the matrix structure where it is possible to belong to two units at the same time.

Figure 5

Aligning Strategy with Structure

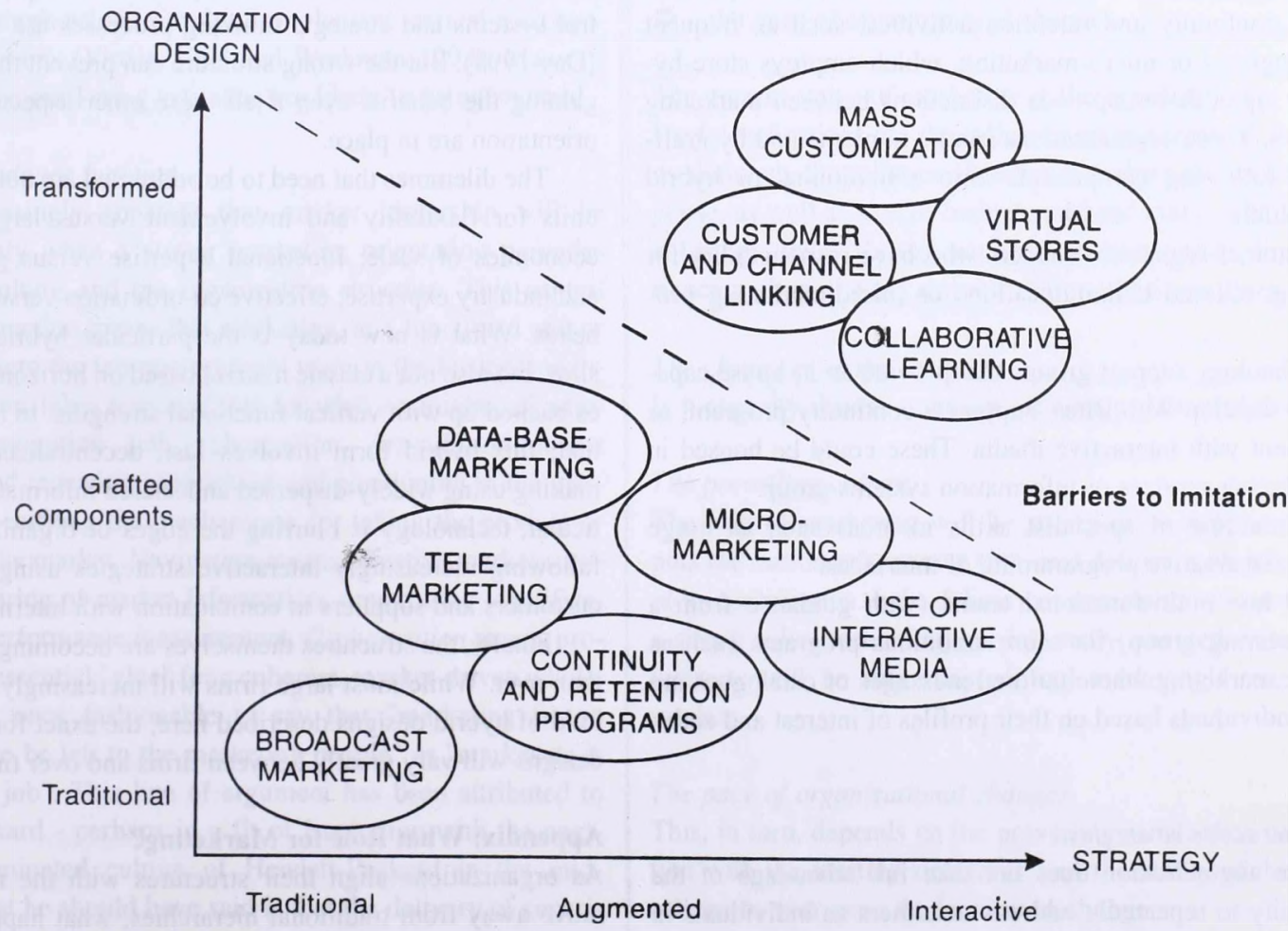




\section{Organizing for Interactivity}

Organizations are being transformed because advances in information technology and growing understanding of the power of teams enables greater dispersion of information and decision making. These more fluid arrangements are ideally suited to the requirements of interactive strategies such as mass customization and collaborative learning. As Figure 5 shows, structure both follows and enables strategies of increasing dialogue and collaboration.

The essence of interactive strategies is the use of information from the customer rather than about the customer. While this is entirely natural for firms with a few sophisticated and well-informed customers, it is a radical departure for those in financial and travel services, apparel, publishing or standard industrial firms that have traditionally used broadcast marketing.

\section{Traditional strategies}

The least interactive configuration, shown in the lower left of Figure 5 , is the traditional broadcast marketing strategy, using mass media and intermediaries to reach large market segments. This approach is well aligned with the traditional functional organization. As the strategy is augmented with interactive elements or becomes completely interactive, an organizational transformation is needed

\section{Augmented strategies}

Some companies augment a broadcast marketing strategy with slightly more interactive approaches. For example, many organizations augmented their traditional media by putting their existing materials on a Web site. More substantial departures involve continuity and retention activities, such as frequent flyer programs or micro-marketing, which employs store-bystore or zip-code-by-zip-code distinctions between marketing programs. These augmentations can be implemented by grafting the following components onto a traditional or hybrid organization:

- Customer-segment managers who have responsibility for designing tailored communications or micro-marketing programs.

2 Technology support groups that provide an in-house capability to develop Web Bites, support a continuity program, or experiment with interactive media. These could be housed in the marketing services or information systems group.

- Outsourcing of specialist skills in areas such as usage tracking, or creative programming of interfaces.

- Ad hoc multi-functional teams (with guidance from a senior steering group) for more ambitious programs such as database marketing where tailored messages or catalogues are sent to individuals based on their profiles of interest and activities.

\section{Fully interactive strategies}

A simple augmentation does not take full advantage of the opportunity to repeatedly address customers as individuals in the light of what has been learned from their previous responses. To exploit this capability, a transformed organizational design is required.

Examples of fully interactive strategies, shown in the upper right of Figure 5, include mass will customization, virtual stores and collaborative learning to fit services to needs. This latter approach was pioneered by Individual Inc and practised effectively by the US armed forces insurance entity USAA. Also included here are the approaches to business partnering used by Astra Merck.

Because strategy and structure are interlinked, one of the advantages for market-driven firms that create transformed organizations and pursue interactive strategies is that competitors may have difficulty keeping up. As illustrated in Figure 5, these interactive strategies are very difficult for companies with traditional structures and strategies to emulate. Barriers to imitation of these strategies give transformed organizations an added advantage over competitors. For example, a traditional pharmaceutical company or an industrial equipment firm selling from a catalog will not be able to match the customerresponsiveness of an Astra Merck or a mass customizer: the differences in strategy, structure, systems and skills are simply too great to bridge. Faced with such impediments, an established firm will have to transform itself with a completely new organizational design or set up an independent unit with a responsive structure.

\section{Conclusion}

Achieving the right structure will not, by itself, ensure marketdriven performance. A market-driven culture, capabilities, control systems and strategic thinking processes are also needed (Day 1998). But the wrong structure can prevent the firm from gaining the benefits even if all these other aspects of market orientation are in place.

The dilemmas that need to be addressed are not new: small units for flexibility and involvement versus large units for economies of scale; functional expertise versus global scale and industry expertise; effective co-ordination versus low overheads. What is new today is the particular hybrid form (not silos, but also not a classic matrix) based on horizontal processes backed up with vertical functional strengths. In today's context, this hybrid form involves fast, decentralized decisionmaking using widely-dispersed and shared information. In particular, technology is blurring the edges of organizations and fallowing increasingly interactive strategies using data from customers and suppliers in combination with internal data.

Finally, the structures themselves are becoming more fluid than ever. While most large firms will increasingly opt for the kind of hybrid designs described here, the exact form of these designs will vary greatly between firms and over time.

\section{Appendix: What Role for Marketing?}

As organizations align their structures with the market and move away from traditional hierarchies, what happens to the 
marketing function? Does it become more central or does it disappear into the fabric of the hybrid organization? Three possible scenarios for the role of the marketing function are:

functional fiefdom;

- subordinate function;

- central guidance function

\section{Functional fiefdom}

Here the marketing function has historically been separate and aloof. It is likely to be the lead function because the industry is customer-driven, and its power is enhanced by controlling access to market information. Its lead role will persist as long as the organization retains a traditional functional or product management structure, or external trends do not cause the balance of power in the organization to shift. However, in markets where the prices and products can be customized at the point of contact with the customer, new approaches will be required so that marketing programs can be launched independently by those closest to the market. In addition, in packaged goods firms, the pressure to respond faster and better to the demands of retailers will enhance the power of the sales and logistics functions.

\section{Subordinate function}

This outcome is most likely for firms in capacity-driven or knowledge-focused industries where the organization structure has evolved into a hybrid form. Marketing people are likely to occupy a subordinate role in sales support activities or as participants in core process teams. This outcome is especially likely when the culture is very engineering or technology driven, and marketing's role is simply to implement tactical merchandising programs (Virden 1995 and Workman 1993). Many of the specialist marketing activities are likely to be outsourced.

\section{Central guidance function}

It is increasingly apparent that market leadership will be attained only when a strong marketing orientation pervades both the culture and the organization structure. This central guidance function means that marketing, as a functional unit or integrated into the top management team in the business planning function, takes responsibility for what we might call articulation, navigation and orchestration. Articulation means defining and renewing proposition and positioning in the market, and specifying the mechanisms for taking the product or service to the market. Navigation means effective market sensing and sharing of market information, opportunity identification, and performance measurement. Orchestration means providing the essential "glue" for a coherent, market-driven whole.

It was once fashionable to say that "marketing is too important to be left to the marketing people" or "marketing is everyone's job". This line of argument has been attributed to David Packard - perhaps in a fit of frustration with the engineering-dominated culture of Hewlett-Packard in the mid1980s. What he should have said is that the delivery of superi- or customer value is everyone's responsibility (Lehman und Jocs 1997). If marketing is everyone's responsibility, then it is nobody's responsibility - and bad things can happen. Listen to Carl Gustin, the Chief Marketing Officer of Kodak, on why his position was formed in 1995 :

"Over time at Kodak we lost our central focus on marketing. Every business unit - and nearly every individual - adopted different marketing theories and practices. Some were strong, some were weak, but the combination was inconsistent.

"And we made a common blunder. Earnest but inexperienced people engaging in marketing tend to resort to promotion: discounts, rebates, coupons, etc. They neglect comprehensive planning strategies. They fail to differentiate their product to command a premium. Worse yet, they risk devaluing the brand - they try to do everything with price

"We knew this wasn't working. We needed to re-establish a strong central marketing competence. We didn't centralize fully, but we formed a single point of accountability und expertise. My job as CMO is to make sure we have great marketing people in each business unit. They must understand the power or our brand, and keep its integrity, its symbolic force, its credibility intact." (Clippinger 1997)

What should be the responsibility of the marketing function? In determining whether marketing serves in a lead or subordinate role, managers should consider:

- the current status of marketing in the organization;

the character of the industry;

the prevailing culture; and

D the pace of organizational changes.

The current status of marketing in the organization.

Useful indications are the influence of marketers in the strategy dialogue, the reliance of decision-makers on market intelligense, as well as size of budget and head-count. The functional background of the top management team and its direct experience with marketing activities offer additional clues.

\section{The character of the industry}

Is it capacity-driven, consumer-driven, or knowledge-driven?

\section{The prevailing culture}

The role of marketing will be strong in an organization that puts the customer's interest first, and defines each job in terms of its contribution to the delivery of superior customer value. In a strong sales, technology, or internally-oriented culture these interests will be subordinated, and marketing's role will be weaker.

\section{The pace of organizational changes}

This, in turn, depends on the prevailing satisfaction or frustration with the existing structures, and the ability of the organizations to overcome the barriers to change. 
Many organizations will decide that marketing has multiple roles. Just as they choose to create hybrid structures rather than fully functional or fully horizontal structures, they will see marketing activities through two lenses. As a specialist activity it provides the expertise in market sensing, customer linking, and channel binding to keep the organization continuously appraised of opportunities and threats in the market. As a general management responsibility - through its leadership of the $\mathrm{CEO}$ and $\mathrm{CMO}$ - it defines and articulates the value strategy, provides aids for navigation through market turbulense and provides the rationale for co-ordinating the core processes. When these responsibilities are effectively carried out all other functions, processes, and activities will be better aligned to the market.

\section{References}

Armstrong, Arthur G., Helene Erright, Elizabeth C. Lempres and Stacey Rauch (1996) What's Wrong with the Consumer Goods Organization? McKinsey Quarterly, 1, 126-135.

Aufreiter, Nora, Mike George, and Liz Lempres (1996) Developing a Distinctive Consumer Marketing Organization, Journal of Market-Focused Management, 3 (1), 199-208.

Boehm, Rodger, and Cody Phipps (1996) "Flatness Forays" McKinsey Quarterly, 3, 128-143.

Boston Consulting Group (1995) reported in Vision of the Future: Role of Human Resources in the New Corporate Headquarters, Washington, DC: The Advisory Board Company.

Cespedes, Frank V. (1995, revised) Astra/Merck Group, Harvard Business School Case 9-594-045 (revised March 1, 1995).

Clippinger, Marni (1997) A Conversation with Carl Gustin, Kodak's Chief Marketing Officer, MSI Review, Fall, p7.

Day, George (1998) What Does it Take to be Market-Driven? Business Strategy Review, 9, 1, pp1-14

Day, George (1999; forthcoming) The Market-Driven Organization, New York: The Free Press.
Evans, Philip B. and Thomas S. Wurster (1997) Strategy and the New Economics of Information Harvard Business Review, 75 (September-October), 70-83.

Hamel, Gary and C.K. Prahalad (1994) Competing for the Future, Cambridge: Harvard Business School Press.

Hammer, Michael (1996) Beyond Reengineering: How the Process-Centered Organization is Changing Our Work and Our Lives, New York: Harper Business.

Lehmann, Donald R. and Katherine E. Jocs (1997) Reflections on the Future of Marketing. Cambridge MA: Marketing Science Institute.

Nonaka, Ikujiro and Hirotaka Takeuchi (1995) The Knowledge-Creating Company, New York: Oxford University Press.

Pangan, V. Kasturi (May 10, 1994) Managing Market Complexity: A Three-Ring Circus, Harvard Business School

Virden, Thomas W. (1995) Can This High-Tech Product Sell Itself? Harvard Business Review (November-December) 24-40

Workman, John P. Jr. (1993) Marketing's Limited Role in New Product Development in One Computer Systems Firm, Journal of Marketing Research, 30 (November 1993), 405-421.

Yetter, Wayne (1995) Wayne Yetter: Astra/Merck; Turns Model to Reality Pharmaceutical Executive, 15

George Day is Geoffrey T. Boisi Professor of Marketing at Wharton Business School, Philadelphia. This article is adapted from a chapter in his forthcoming book, "The Market Driven Organization ", to be published by the Free Press later this year.

The Editorial Board would like to express its gratitude to the author for his kind permission to publish this article in our journal. 